\title{
Ambipolar Low-bandgap Copolymers Consisting of Dithienoketopyrrole for All-Polymer Solar Cells
}

\author{
Marina Ide $^{\mathrm{a}}$, Yoshiko Koizumi ${ }^{\mathrm{a}}$, Akinori Saeki ${ }^{\mathrm{a}, \mathrm{b}, *}$ and Shu Seki ${ }^{\mathrm{a}, *}$ \\ ${ }^{a}$ Department of Applied Chemistry, Graduate School of Engineering, \\ Osaka University, Osaka 565-0871, Japan. \\ b PRESTO-JST, 4-1-8 Honcho Kawaguchi, Saitama 332-0012, Japan.
}

\begin{abstract}
The new low-band gap copolymers containing electron-accepting thienoisoindigo (TIDG) exhibit the low-lying lowest unoccupied molecular orbital (LUMO) at $-3.8 \mathrm{eV}$. This envisions their use as n-type polymer in combination with typical p-type regioregular poly(3-hexylthiophene) (P3HT) towards all-polymer organic photovoltaics (OPV). The alternating fluorene and TIDG copolymer, PFTIDG, shows the electronic absorption maximum at $744 \mathrm{~nm}$ in the film states, of which spectrum is complementary to that of P3HT and thus advantageous for covering the wide solar spectrum. The laser and Xe-flash time-resolved microwave conductivity (TRMC) evaluations were performed for screening the effects of $\mathrm{p} / \mathrm{n}$ blend ratio and thermal annealing in bulk heterojunction framework. The power conversion efficiency of $0.06 \%$ was obtained for pre-annealed P3HT:PFTIDG $=1: 1$ together with a high open circuit voltage of $0.92 \mathrm{~V}$, which is suggestive of ambipolar characteristics of PFTIDG.
\end{abstract}

keywords: bulk heterojunction, organic photovoltaics, low-bandgap polymer, microwave conductivity

\section{Introduction}

Solution-processible printable OPVs have been expected as a promising alternative to costly inorganic counterparts. ${ }^{1-4)}$ The power conversion efficiencies (PCE) of OPVs continue to be boosted up progressively and reached over $10 \%{ }^{5,6)}$ However, it is still lower than the strict criteria for commercialization to substitute the inorganic ones represented by crystalline and poly-crystalline silicon solar cells so far. Improving the PCE requires the simultaneous optimization in well-matched energy levels, electronic absorption, and miscibility between the $\mathrm{p}$ and n-type semiconductors, together with sophisticated device physics. ${ }^{7-10)}$ Low band gap polymers are also particularly important in this context because of their feasibility to cover the broad range of wavelength including near-infrared (NIR) and IR regions of the solar spectrum. Many p-type copolymers mixed with fullerene derivatives represented by [6,6]-phenyl- $\mathrm{C}_{61}$-butyric acid methyl ester (PCBM) have been reported for OPVs. On the contrary, n-type copolymers, of which the electronic absorption properties are superior to fullerenes, are limited, because they have difficulties in accepting and transporting electrons in comparison with PCBM. To date, fluorene-benzothiadiazole (F8TBT) ${ }^{11,12)}$ perylene -bisimide (PDI), ${ }^{13)}$ naphthalenebisimide (NDI), ${ }^{14-}$ 17) and cyano-(p-phenylenevinylene) (CNPPV), ${ }^{18,19)}$ dicyanofluorene, ${ }^{20)}$ bithiazole-benzo thiadiazole, ${ }^{21)}$ and diketopyrrolopyrrole-based polymers, ${ }^{22}$ have been investigated for this purpose, and the highest PCEs of all-polymer solar cells are $1.8-2.7 \% .{ }^{11-13)}$

We have reported the synthesis and characterization of novel TIDG-containing copolymers, where their p-type properties were revealed by filed-effect transistor ${ }^{23)}$ and organic photovoltaics. ${ }^{24)}$ The deep LUMOs of TIDG copolymers at $-3.8 \mathrm{eV}$ are realized thanks to its unprecedented electron withdrawing nature. This motivates us to use the TIDG copolymers as n-type polymer in OPV because their LUMO levels were located in between LUMOs of P3HT $(-2.7 \mathrm{eV})^{25)}$ and PCBM $(-4.0 \sim-4.2 \mathrm{eV}){ }^{26,27)}$ The raised LUMO of the copolymers compared to PCBM can lead to improved open circuit voltage $\left(V_{\text {oc }}\right)$ in the bulk heterojunction (BHJ) with P3HT. Among the reported TIDG-based 


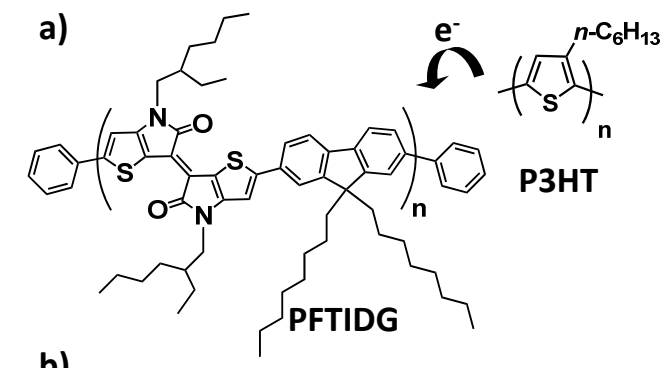

b)

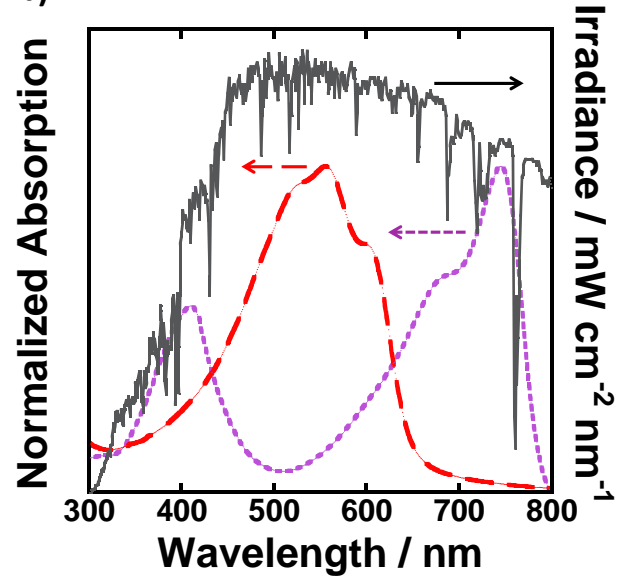

Figure 1. (a) Chemical structures of PFTIDG and P3HT. (b) Normalized absorption spectra of P3HT (red dashed line), PFTIDG (purple dotted line), and solar spectrum (AM1.5G, gray solid line).

copolymers (benzodithiophene, cychlopentadithiophene, and fluorene), fluorene-alt-TIDG copolymer (PFTIDG) as shown in Figure 1(a) was focused, since its HOMO $(-5.4 \mathrm{eV})^{23)}$ is deep enough to prevent undesired hole transfer from HOMO of P3HT $(-4.8 \mathrm{eV}) .{ }^{25)}$ Furthermore, electronic absorption spectra of P3HT and PFTIDG are in the excellent complementary relationship (Figure 1(b)). Prior to device fabrications, we performed a laser and Xe-flash time-resolved microwave conductivity (TRMC) $^{28-30)}$ measurements of PFTIDG: P3HT blends, which tells us about the best $\mathrm{p} / \mathrm{n}$ blend ratio and thermal annealing effects.

\section{Experimental}

PFTIDG was synthesized in the same way with our latest report. ${ }^{23)}$ The weight and number-averaged molecular weights were $4.5 \times$ $10^{4}$ and $2.3 \times 10^{4} \mathrm{~g} \mathrm{~mol}^{-1}$, respectively. Details of the laser-flash ${ }^{28,29)}$ and Xe-flash TRMC ${ }^{30}$ (X-band, 9.1 GHz) were reported previously. The 500 and $680 \mathrm{~nm}$ laser pulses from a nanosecond $\mathrm{Nd}$ :YAG/OPO laser were used as an excitation and the energy density was set at $2.5 \mathrm{~mJ} \mathrm{~cm}^{-2}$ pulse $^{-1}\left(6.4 \times 10^{15}\right.$ and $8.7 \times 10^{15}$ photons $\mathrm{cm}^{-2}$ pulse $^{-1}$, respectively). The power of the white light pulse from a Xe-flash lamp was $0.3 \mathrm{~mJ} \mathrm{~cm}^{-2}$ puls $^{-1}$ (pulse duration is ca. $10 \mu \mathrm{s}$ ). The samples were drop-casted on a quartz plate from chloroform:chlorobenzene $(1: 1.5 \mathrm{w} / \mathrm{w})$ mixture solutions of P3HT:PFTIDG and dried in a vacuum oven. After the preparation of films, they were thermally annealed on a hot plate at 120 or $160{ }^{\circ} \mathrm{C}$ for $10 \mathrm{~min}$. The TRMC experiments were performed under an ambient condition at room temperature.

OPV devices were fabricated according to the previous reports. ${ }^{29)}$ The device configuration was ITO (120-160 nm)/PEDOT:PSS (45-60 $\mathrm{nm}$ )/active layer (ca. $100 \mathrm{~nm}) / \mathrm{Ca}(10 \mathrm{~nm}) / \mathrm{Al}(80$ $\mathrm{nm})$ with an active area of $7.1 \mathrm{~mm}^{2}$. Current-voltage $(J-V)$ curves were measured using a source-measure unit (ADCMT Corp., 6241A) under AM $1.5 \mathrm{G}$ solar illumination at 100 $\mathrm{mW} \mathrm{cm}^{-2}$ (1 sun) using a $300 \mathrm{~W}$ solar simulator (SAN-EI Corp., XES-301S).

\section{Results and discussion}

The molecular weight of the repeating units in PFTIDG is $885 \mathrm{~g} \mathrm{~mol}^{-1}$, leading to an estimate of molar extinction coefficient $(\varepsilon)$ of PFTIDG at the electronic absorption maximum of $745 \mathrm{~nm}$ as $5.2 \times 10^{4} \mathrm{M}^{-1} \mathrm{~cm}^{-1}$ per a repeating unit. The constant observed for PCBM, as a typical n-type material, is less than $10^{3} \mathrm{M}^{-1} \mathrm{~cm}^{-1}$ in the range of $700 \sim 800 \mathrm{~nm}$, suggesting not only the complementary features of the electronic absorption spectrum of PFTIDG to cover the solar spectrum in combination with P3HT but also advantageous to effective harvesting of solar energy in substitution of PCBM and fullerene derivatives. Oscillator strength of the NIR absorption band is also calculated in relation to $\varepsilon$ as follows ${ }^{31)}$;

$$
f=4.3 \times 10^{-9} \int \varepsilon d v
$$

and the numerical integration of the absorption spectrum in figure 1 (a) as a function of wave

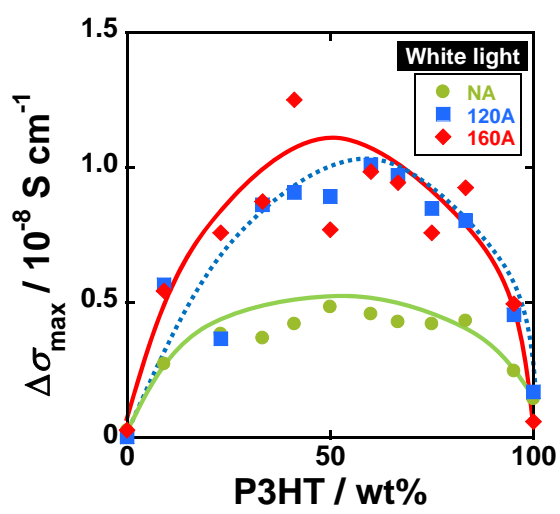

Figure 2. Xe-flash TRMC results of P3HT:PFTIDG blend films. The NA (green circles), 120A (blue squares), and $160 \mathrm{~A}$ (red diamonds) represent the non-thermal treatment, annealing at $120{ }^{\circ} \mathrm{C}$ for 10 min, and $160{ }^{\circ} \mathrm{C}$ for $10 \mathrm{~min}$, respectively. 
number ( $v$ ) deliver the value of $f$ as 0.66 for the lowest energy transition observed for PFTIDG. In spite of the structural basis of alternating repeating units with HOMO-LUMO energy mismatch between TIDG and fluorene units, the value of $f$ is still less than 1 , and suggestive small contribution from intramolecular charge transfer interactions between the units. The spectrum with some significant vibrational structures also supports the simple extension of electronic conjugation along the backbone free from CT interactions. It should also be noted that the value of $f$ is, however, high enough as a principal $\pi$ - $\pi^{*}$ transition chromophore. (As references, the values of $f$ and $\varepsilon$ of the lowest energy transition in P3HT around $550 \mathrm{~nm}$ are $f \sim 0.25$ and $\varepsilon=2 \times 10^{4}$ $\mathrm{M}^{-1} \mathrm{~cm}^{-1}$ per a repeating unit, respectively ${ }^{32)}$.) Highly planar structure of the steady-state TIDG moiety was predicted by DFT calculations, as well as symmetric HOMO and LUMO orbitals extended over TIDG and fluorene units ${ }^{23)}$. This is the case giving the relatively high value of $f$ for the lowest energy transition in PFTIDG.

On the basis of the quantitative analysis of the optical transitions for respective counterparts of PFTIDG and P3HT, the blend film of the polymers were prepared as models of active layers in OPVs and examined by TRMC measurements. Figure 2 plots the transient photoconductivity maxima $\left(\Delta \sigma_{\max }\right)$ of P3HT: PFTIDG films observed by Xe-flash TRMC at different annealing temperatures for $10 \mathrm{~min}$. Apparently the annealing at both 120 and $160{ }^{\circ} \mathrm{C}$ gives a considerable increase in $\Delta \sigma_{\max }$, and the highest $\Delta \sigma_{\max }$ was observed at P3HT $=40 \sim 60$ $\mathrm{wt} \%$ irrespective of the thermal annealing. At the optimized concentration, the value of $\Delta \sigma_{\max }$ becomes 2-fold after thermal annealing at $160{ }^{\circ} \mathrm{C}$ in comparison to that without thermal treatment. This suggests that the formation of appropriate BHJ network and enhanced intermolecular $\pi$-stacking of the polymers were promoted upon thermal annealing. Probably, P3HT and PFTIDG were homogenously mixed just after casting which cannot provide efficient charge transport pathway. The benefit of thermal annealing has been also mentioned in other polymer:polymer solar cells. ${ }^{11,12,17)}$ From the process screening results by Xe-flash TRMC, we expected the best PCE is obtained at $\mathrm{p} / \mathrm{n}$ blend ratio of $1: 1$ with thermal annealing.

Xe-flash TRMC provides overall optoelectronic property of BHJ film including spectrum match with the sunlight, charge carrier generation efficiency, local charge carrier mobility, and its lifetime, which correlates well with the device performance. ${ }^{30}$ To gain access to information about charge carrier lifetime and difference in the initial exciton formation in either P3HT or PFTIDG domains, the laser-flash TRMC experiments under the excitations at 500 and $680 \mathrm{~nm}$ were conducted. Figures 3(a) and (b) show the $\Delta \sigma_{\max }$ dependence as a function of P3HT fraction. The $500 \mathrm{~nm}$ excitation, attributed mainly to P3HT absorption, gave the almost similar trend with Xe-flash TRMC. One of the reasons is that $500 \mathrm{~nm}$ is the main component of white light pulse. However, the annealing effect did not make a significant change in $\Delta \sigma_{\max }$ of laser-flash TRMC, in contrast to the results found in Xe-flash TRMC. This is suggestive of the increased lifetime of charge carrier by thermal annealing, which mediates phase separation between P3HT and PFTIDG and facilitates the formation of long-lived charge carriers.

At $680 \mathrm{~nm}$ which excites predominantly PFTIDG rather than P3HT, the peak position of $\Delta \sigma_{\max }$ of laser-flash TRMC were shifted towards higher content of P3HT of around $80 \sim 90 \mathrm{wt} \%$. This indicates that exciton formed in PFTIDG domain cannot efficiently migrate to the $p / n$ interface and generate charge separated states. In
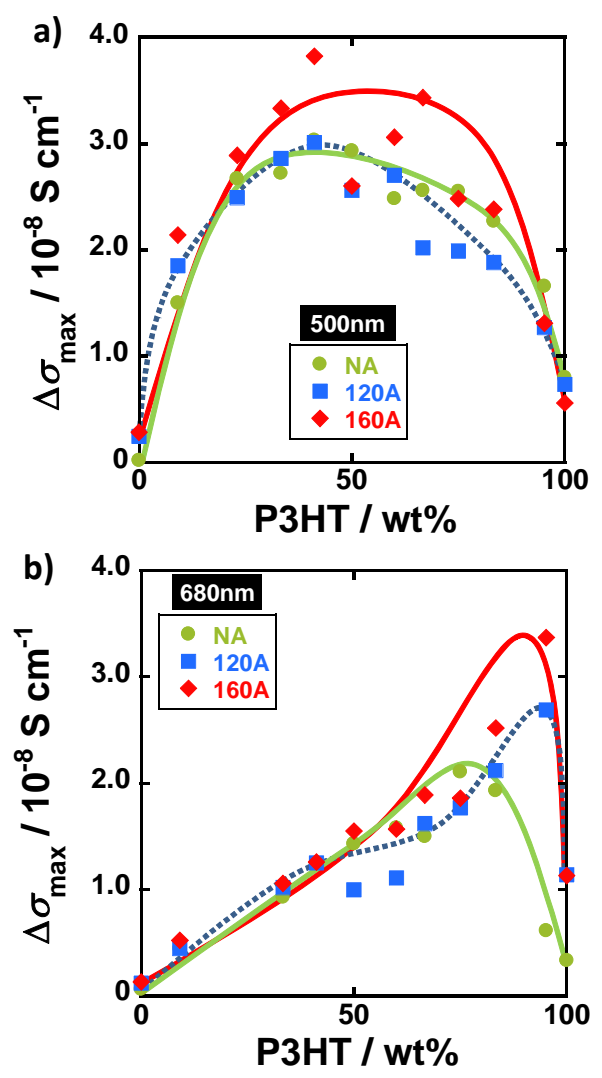

Figure 3. Laser-flash TRMC measurement results of P3HT:PFTIDG blend films upon exposure to (a) 500 and (b) $680 \mathrm{~nm}$. The NA (green circles), 120A (blue squares), and $160 \mathrm{~A}$ (red diamonds) represent the non-thermal treatment, annealing at $120{ }^{\circ} \mathrm{C}$ for 10 $\mathrm{min}$, and $160{ }^{\circ} \mathrm{C}$ for $10 \mathrm{~min}$, respectively. 
other words, exciton diffusion length in PFTIDG is shorter than that in $\mathrm{P} 3 \mathrm{HT}$, as a result of short exciton lifetime and/or small diffusion constant. The steric hindrance exerted by the alkyl chains at 9-position of the fluorene, which occupies orthogonal to the polymer $\pi$-plane is not advantageous for intermolecular exciton migration as well as charge transport. ${ }^{23)}$ This is also evident from the amorphous nature observed in X-ray diffraction (XRD) spectrum ${ }^{24}$ and moderate field-effect transistor (FET) hole mobility $\left(1.1 \times 10^{-3} \mathrm{~cm}^{2} \mathrm{~V}^{-1} \mathrm{~s}^{-1}\right) \cdot{ }^{23)}$ In addition, these results implies the overall TRMC signals are originated from the hole mobility of $\mathrm{P}_{3} \mathrm{HT}^{33)}$ rather than electron mobility in PFTIDG. The impact of thermal annealing was similar to the $500 \mathrm{~nm}$ excitation, reinforcing our presumption on the primary annealing effect on the long-lived charge carriers.

According to the Xe-flash TRMC results, we prepared P3HT:PFTIDG $=1: 1(\mathrm{w} / \mathrm{w})$ devices from a chloroform solution, and examined the effects of thermal annealing. The best PCE was $0.06 \%$ (short circuit current density, $J_{\mathrm{sc}}=0.23$ $\mathrm{mA} \mathrm{cm}{ }^{-2}, V_{\mathrm{oc}}=0.92 \mathrm{~V}$, fill factor, $\mathrm{FF}=0.31$ ) obtained by $120{ }^{\circ} \mathrm{C}$ annealing. The $160{ }^{\circ} \mathrm{C}$ annealing resulted in the same performance of $0.06 \%\left(J_{\mathrm{sc}}=0.23 \mathrm{~mA} \mathrm{~cm}{ }^{-2}, V_{\text {oc }}=0.88 \mathrm{~V}, \mathrm{FF}=\right.$ 0.32 ). On the other hand, the device without thermal treatment did not exhibit diode characteristics at all. Surprisingly, these device characterizations are in perfect accordance with the screening results of Xe-flash TRMC, where both 120 and $160{ }^{\circ} \mathrm{C}$ annealing improved $\Delta \sigma_{\max }$ and the annealing temperature did not give distinguished difference.

The AFM topography and phase images of a blend film of P3HT and PFTIDG employed as an active layer in the optimized OPV device structures are shown in Figure 4. P3HT and PFTIDG are most likely mixed homogenously without forming large respective domains. Despite an appropriate BHJ formation, the obtained PCE of the OPV device $(0.06 \%)$ is
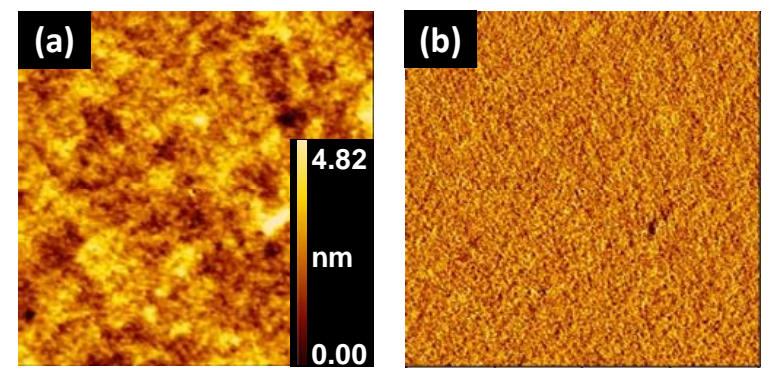

Figure 4. AFM (a) height and (b) phase images of P3HT:PFTIDG $=1: 1(\mathrm{w} / \mathrm{w})$ films after thermal annealing at $160{ }^{\circ} \mathrm{C}$. The size is $2 \times 2 \mu \mathrm{m}^{2}$. considerably lower than the highest value of polymer:polymer solar cells $(\sim 2.7 \%) .{ }^{12)}$ TRMC experiments highlight much larger $\Delta \sigma_{\max }$ at the best $\mathrm{p} / \mathrm{n}$ blend ratio than those of pristine $\mathrm{P} 3 \mathrm{HT}$ or PFTIDG. Therefore, exciton formed in P3HT domain efficiently migrated to the $\mathrm{p} / \mathrm{n}$ interface, giving rise to the total number of charge separated species. Therefore, the low electron mobility in PFTIDG domains might be responsible for the low PCE. The LUMO of PFTIDG is localized relatively on the TIDG unit. $^{23)}$ This situation hampers the effective intermolecular overlap of LUMO as well as the intramolecular hopping between TIDG units. Further elongation of TIDG blocks in the backbone may provide the boosting of electron mobility, leading to the higher PCE in the present system. TIDG-based copolymers have just made its debut on the research field of organic electronics, and thus a variety of molecular designing is left towards the improvement of PCE of all-polymer solar cells based on the electron-accepting TIDG unit.

\section{Conclusion}

We investigated all-polymer photovoltaic cells using P3HT as p-type and PFTIDG as n-type polymers. Xe-flash TRMC revealed the best $\mathrm{p} / \mathrm{n}$ blend ratio lies at around $1: 1$ and thermal annealing enhances the optoelectronic properties, arisen from the improvements in $\mathrm{p} / \mathrm{n}$ phase separation and intermolecular $\pi$-stacking. In combination with the results of laser-flash TRMC excited at 500 and $680 \mathrm{~nm}$, the thermal annealing was found to extend the charge carrier lifetime. The OPV device showed PCE of $0.06 \%$ with a high $V_{\text {oc }}$ of $0.92 \mathrm{~V}$ in contrast to the low $J_{\mathrm{sc}}$ and FF. The device results are in good agreement with the Xe-flash TRMC evaluations. The low performance is probably due to the low electron mobility in PFTIDG phases, rationalized by its amorphous nature and localized LUMO on TIDG unit. TIDG-based copolymers just on their debut still have a large possibility of chemical modifications, which could tune up their optical and electrical properties.

\section{Acknowledgements}

This work was supported by JSPS Funding Program for Next-Generation World-Leading Researches (NEXT Program), the Precursory Research for Embryonic Science and Technology (PRESTO) program of the Japan Science and Technology Agency (JST), Tenure-track program of JST, and KAKENHI from MEXT, Japan.

\section{References}

1. G. Li, R. Zhu, Y. Yang, Nature Photo. 6 
(2012) 153.

2. D. Credgington, J. R. Durrant, J. Phys. Chem. Lett. 3 (2012) 1465.

3. D. Gendron, M. Leclerc, Energy Environ. Sci. 4 (2011) 1225.

4. P. M. Beaujuge, J. M. J. Fréchet, J. Am. Chem. Soc. 133 (2011) 20009.

5. R. F. Service Science, 332 (2011) 293.

6. M. A. Green, K. Emery, Y. Hishikawa, W. Warta, E. D. Dunlop, Progress in Photovoltaics, 21, (2013) 1.

7. L. Dou, J. You, J. Yang, C. C. Chen, Y. He, S. Murase, T. Moriarty, K. Emery, G. Li, Y. Yang, Nature Photo. 6 (2012) 180.

8. Z. He, C. Zhong, S. Su, M. Xu, H. Wu, Y. Cao, Nature Photo. 6 (2012) 591.

9. S. H. Park, A. Roy, S. Beaupré, S. Cho, N. Coates, J. S. Moon, D. Moses, M. Leclerc, K. Lee, A. J. Heeger, Nature Photo. 3 (2009) 297.

10. He, Z.; Zhong, C.; Huang, X.; Wong, W.-Y.; Wu, H.; Chen, L.; Su, S.; Cao, Y. Adv. Mater. 2011, 23, 4636-4643.

11. C. R. McNeill, A. Abrusci, J. Zaumseil, R. Wilson, M. J. McKiernan, J. H. Burroughes, J. J. M. Halls, N. C. Greenham, R. H. Friend, Appl. Phys. Lett. 90 (2007) 193506.

12. D. Mori, H. Benten, H. Ohkita, S. Ito, K. Miyake, Appl. Mater. Interfaces, 4 (2012) 3325.

13. E. Zhou, J. Cong, Q. Wei, K. Tajima, C. Yang, K.Hashimoto, Angew. Chem. Int. Ed. $\mathbf{5 0}$ (2011) 2799.

14. J. R. Moore, S. Albert-Seifried, A. Rao, S. Massip, B. Watts, D. J. Morgan, R. H. Friend, C. R. McNeill, H. Sirringhaus, Adv. Energy Mater. 1 (2011) 230.

15. M. Schubert, D. Dolfen, J. Frisch, S. Roland, R. Steyrleuthner, B. Stiller, Z. Chen, U. Scherf, N. Koch, A. Facchetti, D. Neher, Adv. Energy Mater. 2 (2012) 369.

16. Y.-J. Hwang, G. Ren, N. M. Murari, S. A. Jenekhe, Macromolecules 45 (2012) 9056.
17. K. Nakabayashi, H. Mori, Macromolecules 45 (2012) 9618.

18. M. Granström, K. Petritsch, A. C. Arias, A. Lux, M. R. Andersson, R. H. Friend, Nature 395 (1998) 257.

19. Marc M. Koetse, J. Sweelssen, K. T. Hoekerd, H. F. M. Schoo, S. C. Veenstra, J. M. Kroon, X. Yang, J. Loos, Appl. Phys. Lett. 88 (2006) 083504.

20. C. Vijayakumar, A. Saeki, S. Seki, Chem. Asian. J., 7 (2012) 1845.

21. B. Balan, C. Vijayakumar, A. Saeki, Y. Koizumi, S. Seki, Macromolecules 45 (2012) 2709.

22. W. Li, T. Lee, S. J. Oh, C. R. Kagan, Appl. Mater. Interfaces, 3 (2011) 3874.

23. Y. Koizumi, M. Ide, A. Saeki, C. Vijayakumar, B. Balan, M. Kawamoto, S. Seki, Polym. Chem. 4 (2013) 484.

24. M. Ide, Y. Koizumi, A. Saeki, S. Seki, submitted.

25. J. Hou, Z. Tan, Y. Yan, Y. He, C. Yang, Y. Li, J. Am. Chem. Soc. 128 (2006) 4911.

26. J. M. Lee, J. S. Park, S. H. Lee, H. Kim, S. Yoo, S. O. Kim, Adv. Mater. 23 (2011) 629.

27. Z. Li, S.-W. Tsang, X. Du, L. Scoles, G. Robertson, Y. Zhang, F. Toll, Y. Tao, J. Lu, J. Ding, Adv. Funct. Mater. 21 (2011) 3331.

28. A. Saeki, Y. Koizumi, T. Aida, S. Seki, Acc. Chem. Res. 45 (2012) 1193.

29. A. Saeki, M. Tsuji, S. Seki, Adv. Energy Mater. 1 (2011) 661.

30. A. Saeki, S. Yoshikawa, M. Tsuji, M. Ide, C. Vijayakumar, S. Seki, J. Am. Chem. Soc. 134 (2012) 19035.

31. S. Seki, Y. Koizumi, T. Kawaguchi, H. Habara, S. Tagawa, J. Am. Chem. Soc. 126 (2004) 3521.

32. N. Banerji, S. Cowan, E. Vauthey, A. J. Heeger, J. Phys. Chem. C 115 (2011) 9726.

33. T. Fukumatsu, A. Saeki, S. Seki, J. Photopolym. Sci. Technol. 25 (2012) 665. 